\title{
Das Leben denken
}

Erster Teil

Herausgegeben von

Andreas Arndt

Paul Cruysberghs

Andrzej Przylebski

in Verbindung

mit Franck Fischbach

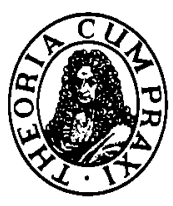

Akademie Verlag 
Redaktionelle Mitarbeit: Julia Brauch

ISBN-10: 3-05-004191-9

ISBN-13: 978-3-05-004191-9

(C) Akademie Verlag GmbH, Berlin 2006

Das eingesetzte Papier ist alterungsbeständig nach DIN / ISO 9706.

Alle Rechte, insbesondere die der Übersetzung in andere Sprachen, vorbehalten. Kein Teil dieses Buches darf ohne schriftliche Genehmigung des Verlages in irgendeiner Form - durch Photokopie, Mikroverfilmung oder irgendein anderes Verfahren reproduziert oder in eine von Maschinen, insbesondere von Datenverarbeitungsmaschinen, verwendbare Sprache übertragen oder übersetzt werden.

Lektorat: Mischka Dammaschke

Einbandgestaltung: Günter Schorcht, Schildow

Satz: Julia Brauch, Berlin

Druck: MB Medienhaus Berlin GmbH

Bindung: Lüderitz \& Bauer, Berlin

Printed in the Federal Republic of Germany 